\title{
“LA FUNDACIÓN DE ASUNCIÓN" O CÓMO ESCRIBIR HISTORIA EN LA ASUNCIÓN DE
}

1890

\section{"THE ASUNCIÓN FOUNDATION" OR HOW TO WRITE HISTORY IN THE ASSUMPTION OF 1890}

Bárbara Gómez1

Enviado: $27 / 07 / 2020$

Aceptado: 26/11/2020

Resumen: En este artículo se analizan las concepciones de historia de los hombres de letras de fines del siglo XIX en el Paraguay a través de las críticas realizadas por Blas Garay a Alejandro Audibert sobre la fecha de la fundación de Asunción. Se desarrolla pormenorizadamente el entramado sociopolítico e historiográfico que implican las críticas históricas tanto para el momento en que se producen, septiembre de 1894, como desde una mirada mas amplia que abarca el periodo de posguerra. Las fuentes utilizadas son los artículos publicados en el diario La Unión, El Pueblo y La Libertad de septiembre de 1894.

Palabras clave: Garay; Audibert; crítica histórica; historiografía paraguaya. 
Abstract: This article analyzes the conceptions of history of the men of letters of the late nineteenth century in Paraguay through the criticisms made by Blas Garay to Alejandro Audibert on the date of the founding of Asunción. The sociopolitical and historiographic framework that the historical criticisms imply both for the moment in which they occur, September 1894, and from a broader perspective that covers the postwar period, is developed in detail. The sources used are the articles published in the newspaper La Unión, El Pueblo and La Libertad of September 1894.

Keywords: Garay; Audibert; historical criticism; Paraguayan historiography. 


\section{Introducción}

En la segunda mitad del siglo XIX, cuando la profesión del historiador no estaba institucionalizada como tal en la región, diversos hombres de letras protagonizaron discusiones acaloradas sobre relatos del pasado que se elaboraban, fundamentalmente, para la consolidación de los estados nacionales. El caso de Andrés Bello y José V. Lastarria de 1844 en Chile y el de Bartolomé Mitre con Dalmacio Vélez Sarsfield en 1864 y, posteriormente, en 1881 y 1882 con Vicente Fidel López en el territorio argentino, son ejemplos clásicos de estas discusiones.

Paraguay no escapó a esas disputas, sin embargo, entre 1864 y 1870 fue escenario de la guerra contra la Triple Alianza -Imperio de Brasil, Confederación Argentina y Uruguay-y los efectos fueron catastróficos para su población. Recién en la década de 1890 se constituyó, en Asunción, una elite intelectual que

pudo permitirse reflexionar, cuestionar, discutir y criticar el pasado nacional y los relatos escritos sobre este. Así, durante la última década del siglo XIX se sucedieron, al menos, cinco críticas historiográficas de ciertos "historiadores" hacia otros². Se identifican cuatro características generales: la arena de discusión siempre fue la prensa; discutían sobre diversos hechos históricos del pasado nacional pero no sobre la Guerra; los que realizaban la crítica pertenecían a una generación más joven que el criticado y ninguna de ellas, o por lo menos no tenemos pruebas aún, produjeron fuertes intercambios entre los implicados: la mayoría de los autores criticados respondieron en una o dos ocasiones. Pese a la falta de "dialogo" entre los "contrincantes" estas discusiones produjeron textos con una erudición extraordinaria a partir de los cuales se pueden

2 La primera fue en mayo de 1894: Manuel Gondra contra José S. Decoud, Alejandro Audibert y Manuel Domínguez. La segunda, septiembre de 1894: Blas Garay contra Alejandro Audibert que tiene un segundo episodio en enero y febrero de 1895. La tercera fue entre marzo y abril de 1897, Blas Garay contra Manuel Domínguez (Cfr. Gómez, 2017). La cuarta fue entre abril y mayo de 1897, Manuel Gondra contra Blas Garay. La quinta fue en el transcurso 1900 Manuel Gondra contra Manuel Domínguez. 
analizar las concepciones de historia en pugna en el periodo.

La polémica entre Cecilio Báez y Juan E. O'Leary que, por su duración, el tenor, la envergadura y las repercusiones que tuvo, es considerada como fundante para la historiografía paraguaya (Brezzo, 2008; Sansón Corbo; 2015) se produjo iniciado el nuevo siglo, entre 1902 y 1903 . Sin embargo, ninguno de sus protagonistas había participado de las discusiones de la década anterior, aunque por el espacio de la contienda, también la prensa, y la edad de los contrincantes, se puede reconocer ciertas continuidades.

Siguiendo a Alejandro Eujanian (2003) concebimos que la crítica histórica es una herramienta que fomenta la definición de la profesión de historiador en un periodo donde ésta no está institucionalizada. El análisis de diversas discusiones es un espacio fundamental para, por un lado, reconstruir cómo se concebía la historia, qué fuentes utilizaban, cuál era el espacio para la interpretación y qué criterios consideraban necesarios para redactarla y, por otro, para iden- tificar cuál era la función social que sus productores le daban.

Así, partimos de la discusión ocurrida en septiembre de 1894 entre el joven Blas Garay estudiante de derecho y redactor del diario La Unión y el jurista Dr. Alejandro Audibert. A través de ocho artículos publicados entre el 4 y el 17 de septiembre, Garay "corrigió" los errores en que incurrían los historiadores anteriores, los contemporáneos y especialmente los cometidos por Audibert sobre la fecha de fundación del fuerte de Asunción. El joven de por entonces 21 años, desplegó todas las fuentes y bibliografía a disposición para sustentar que la fundación se había realizado en 1537 y no en 1536 como "erróneamente" se afirmaba. El Dr. Audibert, entonces con 35 años, respondió una única vez desde las columnas del diario El Pueblo, manteniendo su postura y aclarando que no discutiría con alguien que se posicionaba en la actitud de un "maestro de historia".

El objeto de la crítica de Garay era el libro que Audibert había publicado en 1892, "Los Límites de la Antigua Provincia del Paraguay". La obra de más 
de trescientas páginas comenzaba con las expediciones de los españoles a tierras guaraníes y llegaba hasta antes de la independencia del Paraguay en 1811. El objetivo era demostrar los títulos históricos que tenía Paraguay desde los inicios de la colonia sobre los territorios del Chaco en litigio, por ese entonces, con Bolivia. El espacio que el libro dedicaba a la fecha de fundación de Asunción era mínima e irrelevante en el marco del objetivo principal por el que había sido redactado.
En esta investigación buscamos, desde una perspectiva historiográfica, analizar la concepción de historia que tenían los protagonistas, lo que implica revisar sus influencias intelectuales, las formas de trabajo con las fuentes documentales -análisis interno y externo-, si es que lo hacían y los criterios utilizados para redactar los textos. De igual forma y directamente articulada a la perspectiva historiográfica procurar comprender qué motivó a Garay a realizar la crítica sobre una temática secundaria de una obra que se había publicado hacía más de un año.

\section{Estado del arte}

Las investigaciones sobre historiografía paraguaya han tenido un desarrollo exponencial en las dos últimas décadas, enriqueciendo profusamente las discusiones sobre la temática, los trabajos de Liliana Brezzo, Tomas Sansón Corbo, Herib Caballero Campos, Ignacio Telesca, Claudio Fuentes Armadans y Matías Borba son fundamentales en este proceso.

Sobre el periodo abordado especial mención merecen los análisis realizados por Brezzo sobre la polémica Báez y O'Leary

(2008) y "La historia y los historiadores" (2010), "Reparar la nación" discursos históricos y responsabilidades nacionalistas en Paraguay" (2010), "El Paraguay en cinco momentos historiográficos: retos y perspectivas" (2009), por nombrar algunos. Las investigaciones en perspectiva comparada sobre la protohistoriografía paraguaya de fines del siglo XIX y la formación del campo historiográfico de Sansón Corbo (2015 y 2019) también ha sido fundamentales para pensar el periodo. Sobre discusiones previas al periodo ana- 
lizado destacamos "Sarmiento vs Cañete: polémica previa al surgimiento del novecentismo" de Fuentes Armadans (2016). Los textos, ya clásicos, sobre historia intelectual sobre las letras paraguayas de Carlos Centurión (1948) y sobre el novecentismo paraguayo de Raúl Amaral (2006) son sustanciales en esta investigación.

Sobre la obra de Blas Garay, específicamente, están los trabajos que hemos realizados analizando la concepción de historia en su libro "La revolución de la Independencia" de 1897 (Gómez, 2016), las críticas que protagonizó con Manuel Domínguez en 1897 sobre la dictadura francista (Gómez, 2017) y su trayectoria educativa que conformó su concepción de historia (Gómez, 2019). De los varios textos de Telesca resaltamos "Blas Garay y el Prólogo a del Techo: inventando el Paraguay” (2012) y “La
República de los historiadores del Paraguay posbélico" (2013).

Sobre la obra histórica de Audibert no hay trabajos específicos pero si sobre su papel en los litigios con Bolivia. Para comprender el trasfondo político y el uso de la historia en los litigios por las cuestiones de límites con Bolivia a fines del siglo XIX, las investigaciones de Ricardo Scavone Yegros, especialmente a "Las relaciones entre Paraguay y Bolivia en el siglo XIX" de 2004, son de lectura imprescindible. Y para el contexto político y socioeconómico del periodo "El renacimiento de la república paraguaya. La primera era colorada: 1878-1904" de Harris G. Warren de 1985.

En el siguiente apartado contextualizamos la situación de Paraguay en 1894, presentamos a los protagonistas, articulamos las relaciones entre estos y la situación sociopolítica del periodo. 


\section{Apartado I: Contexto}

Luego de finalizada la guerra las potencias aliadas -Brasil y Argentina- siguiendo con lo pautado por el Tratado Secreto de la Triple Alianza de 1865, firmaron tratados de límites, navegación y amistad con Paraguay, lo que provocó la pérdida de 156.415 km2 (Kleinpenning, 2011, p. 38). Los últimos territorios en litigio con Argentina fueron llevados a arbitraje, con un resultado positivo para Paraguay. Firmados los tratados, faltaba definir los límites con Bolivia, tercer país con quien tiene frontera.

Las cuestiones de límites con Bolivia venían de larga data incluso de antes de la Guerra, hay tratativas y conversaciones ya en la década de 1850 (Scavone, 2004). El año 1894 encuentra a Paraguay y a Bolivia en conversaciones por la firma de un tercer tratado de límites. Los anteriores habían sido firmado en 1879 entre los plenipotenciarios José Segundo Decoud y Antonio Quijarro, cuyos resultados no fueron aprobados por los poderes legislativos de ambos países. Recordemos que entre 1879 y 1883 Bolivia libró, junto a Perú, la guerra del Pacífico contra Chile, por la que perdió su salida al mar. En este nuevo panorama geopolítico se negoció el segundo tratado de límites con Paraguay en 1887 entre los plenipotenciarios Benjamín Aceval e Isaac Tamayo. El objetivo principal de Bolivia era tener acceso a alguna vía fluvial que le permitiera la tan ansiada y necesaria salida al mar. Este segundo tratado tuvo el mismo fin que el primero (Scavone, 2004).

Así como Bolivia había sufrido cambios entre el primer y el segundo tratado Paraguay también habría vivenciado modificaciones en otros órdenes. Finalizada la guerra contra la Triple Alianza, además de estar destruido económicamente el país había quedado lleno de deudas con las potencias vencedoras. Por tal razón, a inicios de la década del 70 se pidió un préstamo a la banca inglesa privada, del que solo llegó un $30 \%$ del monto total. A medida que avanzaban los años Paraguay continuaba pobre y además endeudado doblemente con la banca inglesa y con las potencias aliadas. A inicios de la década del 80 el gobierno tomó una decisión, que ha 
sido ampliamente analizada y discutida: la venta de tierras y yerbales fiscales (Warren, 1985; Herken Krauer, 1984). Lo más controvertido de las leyes de 1883 y 1885 no era tanto la venta de tierras en sí, teniendo en cuenta la necesidad imperiosa que tenía el país de pagar sus deudas y la dificultad temporal de diseñar otras estrategias, sino que el mínimo de compra de tierra que había que adquirir excluía de hecho a los pequeños y medianos campesinos paraguayos empobrecidos por las pésimas condiciones de posguerra. Esta venta potenció aún más el latifundio ya existente y dejó en manos de capitales extranjeros grandes extensiones de tierra. En este contexto la zona del Chaco, en litigio con Bolivia, que aparecía como un lugar lejano, salvaje e impenetrable comienza a ser percibida como un territorio que permitiría generar riquezas. Lo que hace cambiar necesariamente la idea que tenían los gobiernos sobre el territorio (Chesterton, 2013).

El Dr. Audibert, que era opositor al gobierno, fue un célebre detractor de los Tratados, consideraba que el gobierno estaba regalando territorio a
Bolivia. Desde las columnas de los diarios de oposición “El Paraguayo", “El Independiente" y “La Democracia" expresó su punto de vista contra los tratados (Scavone, 2004: 438). Audibert consideraba que antes de firmar un tratado, era necesario revisar...

\section{"el principio del uti pos- sidetis resuelve la causa con tal claridad que (...) es permitido afirmar sin controversia, que á cada Estado le corresponde el territorio que poseía legamente al separarse de la común Madre-Pá- tria, porque ambos países estaban sujetos á un mismo absoluto soberano, cuya voluntad expresada en cualquier forma era ley, y por cuya ley común estaban fijados sus respectivos dominios" (Audibert, 1892: p. 6).}

Antes que conversaciones entre plenipotenciario era necesario exponer los títulos de ambos países. La posición del jurista era que "la ley por la cual debe resolverse la cuestión está determinada por el expreso consentimiento de las cancillerías de los dos gobiernos sobre el 
citado principio -uti possidetis-, y toda la dificultad se reduce á investigar los límites de la antigua provincia o gobernación de la Asunción del Paraguay, con las provincias o gobernaciones del coloniaje español, colindantes con ella" (Audibert, 1892: p. 6-7).

Ante el rechazo del segundo tratado en marzo de 1890 el presidente Patricio Escobar encargó al doctor Alejandro Audibert "la preparación de una memoria respecto a los derechos del Paraguay sobre el Chaco, y este la entregó en octubre del mismo año, en dos tomos foliados y encuadernados" (Scavone, 2004: p. 438). El pedido del presidente nacía de una solicitud realizada por la Cámara de Senadores en una sesión secreta del 12 de septiembre de 1889 "con el fin de mejor proveer sobre el tratado de límites sometido a su consideración" (Scavone, 2004: p. 433). Esta había sido la última sesión del año y se había decido postergar hasta el año siguiente el estudio del arreglo territorial en torno al ya caduco Tratado de 1887. Si bien el jurista era miembro activo de la oposición del grupo político que estaba en el gobierno, consideramos que el oficialismo lo contrató por la solidez de su argumento y por el prestigio que tenía.

En diciembre de 1892 Audibert, usando como base la Memoria presentada al gobierno en 1890 y ampliando la información, publicó en Buenos Aires su obra titulada "Los límites de la Antigua Provincia del Paraguay. Primera parte" donde daba cuenta de los títulos históricos del Paraguay sobre el territorio en litigio. En el Prólogo explicitaba su perspectiva para solucionar el conflicto sobre los territorios del Chaco

"El asunto era y es asi esencialmente histórico y práctico, no siendo posible resolverlo acertadamente, sin estudiarlo con madurez, en los documentos o títulos de gobernadores, en las Leyes de Indias, en las obras de los historiadores y geógrafos, en los juicios de los peritos, y en las discusiones que ilustran la verdad y el derecho de los Estados. Por consiguiente, antes de celebrarse un tratado de límites, debió agotarse los medios que la ciencia 
y la experiencia enseñan para descubrir la verdad, puesto que no se trataba de crear nuevos linderos a las naciones contratantes, sino de consignar las divisiones existentes, desde los más remotos tiempos del coloniaje. De esta consideración nace que, fueron muy ligeros e incalificables los mandatarios de la República, al arreglar los límites del Estado con Bolivia, sin exhibición de títulos, discusión ni examen de los antecedentes de la historia, en los tratados de 1879 y $1887^{\prime \prime}$ (Audibert, 1892: p. 7).

Audibert omitió aclarar en el Prólogo que la base del libro era el informe de 1890 que había redactado a pedido del gobierno de Patricio Escobar (1886-1890). La omisión tiene sentido en tanto que el autor se posiciona claramente contra la forma en que el grupo político gobernante aborda la negociación de los límites con Bolivia. Audibert conformaba la oposición al gobierno y especialmente se oponía a la estrategia de negociación. La publicación de la obra tuvo cobertura en
Asunción los primeros días de 1893 e incluso el Prólogo salió publicado en El Independiente los días 10 y 11 de enero de 1893.

Pese a la queja constante de Audibert de que el gobierno no tenía en cuenta su sugerencia, en el año 1893 el Senado y la Cámara autorizaron al Ejecutivo adquirir la "obra completa" del Dr. Audibert, "en la cantidad de 500 ejemplares y a un precio que no exceda de treinta pesos fuertes" (Registro Oficial, 1893: 49). Las obras compradas serían repartidas a "las oficinas públicas, legaciones y consulados nacionales y extranjeros y a gobiernos amigos a medida que se vaya recibiendo" (Registro Oficial, 1893: 49).

En otro ámbito, desde 1878 en Paraguay gobernaba el mismo grupo político que recién en 1887 se conformaría como partido político bajo el nombre de Asociación Nacional Republicana, mas conocido como partido Colorado (Warren, 1985). Se formaron como tal ya que la oposición se había organizado para enfrentarlos bajo la denominación de Centro Democrático y luego rebautizado como partido Liberal. A 
fines de 1894 culminaba su mandato el presidente Juan Gualberto González cuando miembros de su partido, la ANR, pero de facciones opositoras -caballeristas y egusquicistascon recursos financieros provenientes de Brasil se unieron y lo derrocaron en un golpe de estado, el 9 de junio, arguyendo que González pretendió heredar la presidencia a alguien de su familia (Warren, 1985; Lewis, 1993, Doratioto, 2011).

La presidencia quedó a cargo del vicepresidente Marcos Morínigo y como resultado de la unión de las facciones de la ANR se conformó una chapa presidencial que unificaba a ambos grupos compuesta por

Juan B. Egusquiza y Facundo Insfrán, quienes gobernaron el país entre 1894 y 1898 y realizaron un cambio sustantivo en la política de las relaciones internacionales, en especial a los vínculos con los títulos históricos del Paraguay.

En este tiempo Blas Garay militaba en el partido colorado y era un ferviente defensor de las políticas públicas de su partido. El diario La Unión, donde publicó la crítica a Audibert, había sido fundado en junio de 1894 y duró hasta noviembre del mismo año. El nombre completo de La Unión era "Órgano de Partido Nacional Republicano" y en el inicio estaba escrito "Candidatos del Partido Nacional Republicano para el 7 periodo constitucional General Juan Bautista Egusquiza y médico Facundo Insfrán". Sus principales redactores eran Blas Garay y Fulgencio R. Moreno. Su nombre, simbolizaba la unión de los grupos antagónicos que componían al partido Republicano. Se han conservado desde el número 23 con fecha del 6 de julio y hasta el 30 de noviembre número 147, fundamentales para nuestra investigación.

Audibert era un militante de los primeros tiempos del Centro Democrático, oposición de la ANR y en 1894 tenía activa participación en el diario El Pueblo, órgano oficial del partido.

Desde ambos diarios, en varias oportunidades, Garay y Audibert habían intercambiado opiniones opuestas en torno a decisiones políticas del gobierno. En los meses previos a la crítica, en Asunción se estaban llevando a cabo las conversaciones para 
la firma del tercer tratado con Bolivia entre los plenipotenciarios Gregorio Benites y Telmo Ichaso. La posición de Audibert se mantenía firme, se debían análizar de los títulos que justifiquen los derechos de los países sobre los territorios del Chaco. Opinaba que el tratado debía ser un tema para resolver en el mandato que se iniciaría en noviembre de 1898. Como los tratados exigían la aprobación del Legislativo Audibert estimaba que era mejor esperar al inicio del nuevo gobierno y que se realicen las primeras elecciones legislativas para que recién en ese momento se firmara el tratado. Esta espera estratégica permitiría que mientras tanto se analicen los títulos (El Pueblo, agosto de 1894).

El año en que se produce la disputa con Audibert, Blas Manuel Garay de 21 años (18731899) estaba culminando de cursar y rendir todas las materias de la carrera de Derecho, había ingresado el año anterior. Según consta en la Memoria de la Enseñanza Secundaria y Superior de la República correspondiente al año académico de 1894-1895³ (Revista de la Universidad Nacional, 1895), está registrado que el alumno Garay, de 21 años de edad, en el año académico 1894-1895, correspondiente a su segundo año en la facultad, había cursado y rendido todas las materias correspondientes al tercer año, también había rendido como libre las cuatro materias correspondientes al año cuarto año, así como las cuatro materias correspondientes al quinto curso. O sea que para enero de 1895 Garay ya había aprobado todas las materias de la carrera, solo le quedaba el examen general para optar por el título de doctor en Derecho y Ciencias Sociales, lo obtuvo a inicios de 1896 (Amaral, 2004).

Es oportuno comentar aquí que el Dr. Audibert era profesor de Derecho Constitucio-

3 Redactada por José P. Díaz, secretario del Consejo Secundario y Superior, publicada en la Revista de la Universidad Nacional, en el año 1895, Cuadro "Relación nominal de alumnos pensionados, libres matriculados en el presente curso en asignaturas de Enseñanza Secundaria y Superior, con expresión de la edad, lugar de nacimiento, punto de donde proceden, su eliminación o baja voluntaria de la matricula oficial, exámenes que han rendido en el periodo ordinario y clasificaciones obtenidas.". 
nal de la Universidad Nacional, mientras Garay era estudiante (Rivarola Paoli, 2012: p. 901).

Garay sobresalía por su precocidad, inteligencia y capacidad de trabajo. Estando aún en el Colegio Nacional participó junto a Manuel Domínguez y Fulgencio R. Moreno en el periódico El Tiempo (Cano Radil, 2011: p. 14). Durante su corta carrera universitaria además de escribir en La Unión participó como cronista y redactor en "La Patria", órgano caballerista fundado por Gregorio Benites, también lo hizo en “La Opinión” y “La Semana” (Centurión, 1948: p. 132).

Las paradojas de la historia muestran que luego del retraso de la aprobación legislativa del tercer tratado de límites con Bolivia, en julio de 1895, por ley se autorizó el envío de un comisionado especial "que se constituya a los archivos de España y haga un estudio de los documentos relativos a la historia y límites del territorio del Paraguay" (Registro Oficial; 1895: p. 82). Garay fue designado para desempeñar el cargo (Registro Oficial; 1895: p. 133). Estuvo dos años en España, tiempo en que hizo copiar 1.317 documentos con 14.914 fojas (Cardozo, 1959: p. 112). Además publicó cuatro obras fundamentales para la historiografía paraguaya. Los libros de ese periodo son considerados como los primeros textos de historia escritos con rigor científico por un paraguayo, en este sentido se consideran fundantes de la profesión de historiador moderno (Brezzo, 2011; Gomez, 2017).

Luego de su estadía en el viejo continente, Garay volvió a Paraguay y fundó su propio diario, La Prensa, tomó distancia del partido Colorado y criticó duramente las políticas del gobierno de Egusquiza y de su sucesor Emilio Aceval. Murió a causa de un duelo en diciembre de 1899. La intensidad de su vida fue extraordinaria.

Los artículos analizados en este trabajo pueden ser considerados como unos de sus primeros escritos de historia. Revisar estos textos iniciales valen por la calidad historiográfica que contienen y porque indican el acceso a la bibliografía existente en Asunción en ese periodo entre otras cosas. 
En el siguiente apartado nos adentramos a las críticas históricas de Garay analizándolas historiográficamente, sin perder de vista el entramado sociopolítico en el que se producen.

\title{
4. Apartado II: La Crítica
}

El primer artículo salió el aficionado", aparecía en la tercera 4 de septiembre de 1894 en La Unión, era una nota al director del periódico, firmado por “Un columna de la primera hoja bajo el título "HISTORIA. Fundación de Asunción" y explicaba que:

\begin{abstract}
"Alentado por la buena acogida que este diario se dispensa á todo lo que de algún modo pueda redundar en provecho de la juventud estudiosa, me permito dirigirle estas líneas que sinceramente expongo ciertas dudas mías sobre un punto histórico para nosotros los hijos de esta tierra muy importante y que ha sido a mi ver muy a la ligera estudiado hasta ahora, o mejor dicho, que según sospechas que creo fundadas, se ha dado por resuelto bastante errónea y precipitadamente me refiero a la fecha en que se fundó la ciudad de Asunción." (La Unión, 4 de septiembre de 1894).
\end{abstract}

Garay escribe como representante de la "juventud estudiosa", sujeto nombrado en diversos textos de hombres de letras del periodo. Bajo el seudónimo de "Un aficionado" criticaba a Audibert y todos los historiadores anteriores que escribieron sobre el tema, señalaba que "volviendo a mis dudas sobre la fecha dada por la casi totalidad de los autores (...), diré que no obstante la autoridad de los que la abonan, es muy fácil de advertir su inverosimilitud con poco que sobre ella se medite." (La Unión, 4 de septiembre de 1894). La inverosimilitud estará asentada en las fuentes que utilizaban para determinar la fecha de la fundación. Su crítica se concentraba en el uso que se le daba al libro del soldado bávaro Ulrico Schmidel (1510? -1597?) “Historia y descubrimiento del Rio de la Plata 
y Paraguay" como fuente clave por haber sido testigo presencial. Objetaba en estos términos:

"a pesar del respeto que me merece la afirmación de nuestro Dr. Audibert, que en la nota de la página 48 de su obra titulada Los límites (...), escribe que participa de la opinión de aquel [schmidel] Ruiz Diaz de Guzmán y el padre Pedro Lozano, cometiendo un error garrafal, indisculpable en él más que en nadie y que revela muy escasa probidad científica" (La Unión, 4 de septiembre de 1894).

La acusación de cometer errores garrafales a causa de "falta de probidad científica" será mal recibida por Audibert. Después de este lapidario juicio, "el aficionado" ruega porque el jurista le quite su duda "como considero que este ilustrado paraguayo [Audibert] habrá compulsado, como es deber de todo historiador concienzudo, muchos datos para decidirse por tal fecha, á el me dirijo, rogándole que me saque de esta duda públicamente" (La Unión, 4 de septiembre de 1894).
El trabajo del historiador "concienzudo" que tiene probidad científica, compulsa todas las fuentes disponibles y elige la más verosímil, de esta forma evita cometer errores garrafales indisculpables. El estudio de la historia no se puede hacer a la ligera. Esto sería una primera aproximación que hacemos a como Garay concibe el trabajo del historiador.

El contexto presentado en el apartado anterior permite intuir que tras esa necesidad imperiosa de aclarar la fecha de fundación de Asunción de parte del representante de la juventud estudiosa, había intereses políticos partidarios vinculados a las conversaciones sobre el tercer tratado de límites que se estaba negociando con Bolivia. Nuestra hipótesis es que, aunque las críticas señaladas por Garay eran correctas, el objetivo principal de éstas era, de alguna forma e indirectamente, desautorizar las críticas de Audibert al gobierno.

Esta hipótesis conduce a una serie de interrogantes: ¿era posible que un joven periodista de un órgano gubernista y estudiante de derecho desacreditara la autoridad y el prestigio de 
quien había sido presidente del Superior Tribunal de Justicia, quien además era visto como un patriota porque defendía los territorios nacionales? Recordemos como en el Prólogo de "Los Límites..." Audibert definía su trabajo en estos términos "ante la decadencia del patriotismo, nos resolvimos hacer algunos apuntes históricos, en los cuales anotamos los límites, títulos de dominio y actos de jurisdicción ejercidos por el gobierno de la Asunción del Paraguay, desde los primeros tiempos del descubrimiento y conquista del Río de la Plata." (Audibert, 1892: 7-8).

Otro de los interrogantes que surgen es cuál fue la repercusión que tuvo la crítica en otros periódicos de la época, ya que, como ya hemos explicado, la prensa era el espacio, por excelencia, de expresión de estas tensiones.

Antes de responder estos interrogantes veamos los términos en que respondió Audibert.

El 5 de septiembre apareció la respuesta en EI Pueblo

"Con motivo de artículo de un "aficionado» que
La Unión de ayer publicó, hemos hecho apersonar a nuestro reporter al doctor Audibert para preguntarle si iba a responder a las dudas del aficionado. Contestó el doctor que no tenía tiempo para desvanecer dudas de una persona que habla con la autoridad de un maestro de Historia" (El Pueb/o, 5 de septiembre de 1894, la cursiva es nuestra).

Para Audibert no tenía sentido dialogar con alguien que se consideraba con más autoridad que cualquier historiador reconocido hasta ese momento y que además no respetaba la autoridad de estos. Seguidamente aclaraba "que iba aprovechar la ocasión de rectificar los errores materiales que contiene «Los límites (..), en la parte a que se refiere [el aficionado]." (El Pueblo, 5 de septiembre de 1894).

Explicaba, "estos errores y varios otros existen porque en la premura de la impresión se han deslizado; pero con un poco de atención y buena fe, recurriendo a las fuentes se notan que son errores materiales y no falta de probidad como asegura el 
aficionado de La Unión." (El Pueblo, 5 de septiembre de 1894). La justificación de Audibert es precaria, parte del supuesto que el lector conoce del tema y sugiere que sea el propio lector el que consulte las fuentes para sacarse las dudas, lo que es objetable porque las fuentes no estaban a disposición y era el historiador quien debía dejar claro esto. En el Prólogo de "Los Límites..." expresaba la idea de que él no estaba hablando de temas nuevos, lo novedoso era mostrar que los derechos de Paraguay sobre los territorios en litigio siempre estuvieron ahí.

\section{"En esta Primera Parte que publicamos, nada hay pues nuevo, sino el trabajo de recoger de las páginas de la Historia del Colo- niaje, los títulos y actos de jurisdicción del Para- guay sobre el territorio del Gran Chaco, omitiendo lo incongruente y espre- sando lo que concierne al caso, con el objeto de hacer resaltar el derecho incontestable de la Repú- blica sobre dicho territo- rio." (Audibert, 1892: 21).}

En el artículo de El Pueblo se le preguntaba a Audibert ¿cuándo se fundó el fuerte de la Asunción? Para el jurista fue en 1536, él dice que citó todas las versiones que se conocen, las que creen que fue en 1539 , en 1536, en 1537, pero él se inclina por la del 1536 porque es la que plantea Lozano y se decide por esta fecha, por la autoridad que representa Lozano en el tema. Explicaba que citaba todas las opciones que había para que el lector conozca las divergencias que existían.

"Al citar a Ruiz Diaz de Guzmán, Lozano y Schmidels, fue mi objeto llamar la atención sobre la diverjencia de opiniones que á este respecto existían, y especialmente sobre el error del último. El lector al revisar las citas tenía forzosamente que notarlas; por consiguiente, una cita falsa no tenía objeto, sería contraproducente y solo se concebiría en algún aficionado de mala fe." (El Pueblo, 5 de septiembre de 1894).

Es real que hacer una cita falsa no tenía ningún objeto ni 
sentido, pero no queda claro en el libro cuál es la fecha correcta, justamente porque él cita todas las fechas y no explicita cual es la correcta. Este es el punto que le va a reclamar Garay, que un buen historiador debe esclarecer estos aspectos.

El artículo culmina con la propuesta de Audibert para que "el aficionado de La Unión prestaría un gran servicio á la Historia, si demostrase el error en que vivimos." (El Pueblo, 5 de septiembre de 1894).

Retomando uno de los interrogantes que habíamos planteado consideramos que la respuesta de Audibert indica que no se vio afectado con la crítica del joven estudiante. Mantiene sus cátedras en la Universidad, mantiene su vida cultural e intelectual. Fue invitado, incluso, por José Segundo Decoud a conformar el Instituto Histórico del Paraguay en noviembre de 1895, a instancias del Dr. Cecilio Báez (Gomez, 2019a: 135). Lo que induce a preguntarnos sobre cómo se percibían ellos mismos y como eran percibidos por sus contemporáneos.
Ambos autores se consideraban historiadores, pero Audibert no lo veía a Garay como tal. Cuando Audibert publica "Los Límites..." lo hace desde una posición de jurista y patriota, lo que no se contradice con la figura de historiador del periodo. Garay por su parte se percibe primero como historiador y desde esa posición patriota "hijo de estas tierras", esclarecedor de los fenómenos que son concebidos erróneamente desde siempre. De modo general, se autoperciben de forma similar, pese a la asimetría de Audibert sobre Garay. La diferencia radicaba en la percepción que había en el medio cultural, político e intelectual.

Citamos las apreciaciones de otro representante de la "juventud estudiosa", contemporáneo a Garay y miembro del mismo partido político de Audibert, Manuel Gondra (18711927), quien en el marco de unas críticas históricas hechas en mayo de 1894 a un Folleto publicado en honor a los próceres de la Independencia declaraba:

"tenemos a la palabra del Dr. Audibert un respeto que la del señor 
Decoud no nos puede inspirar. Diremos porqué. El señor Decoud no puede considerarse todavía para la naciente literatura paraguaya sino una esperanza, pues no ha producido hasta ahora nada que lo haga acreedor al título de historiador o literato. Audibert, por el contrario, es autor de la obra de mayor aliento que haya salido de la pluma de escritor paraguayo alguno, y se ha conquistado con su notable estudio sobre Los Límites de la antigua provincia del Paraguay un lugar distinguido entre los eruditos e historiadores del Rio de la Plata. (Gondra, 1996: 87).

Las palabras de Gondra son claras, Audibert es historiador porque tiene una obra histórica que le acredita el título como tal. Garay, en ese momento y a los ojos de sus contemporáneos, todavía no llegaba a la categoría de "esperanza". Dos años después esto cambiaría radicalmente.

Articulado a la percepción que se tenía sobre Garay respondemos al interrogante sobre cuál fue la repercusión de la crítica. Ninguno de los siete artículos donde Garay desarrolló la historia de la fundación de Asunción desde el 10 al 17 de septiembre de 1894, mereció una línea de El Pueblo o de La Democracia. Este último era un periódico que se publicaba desde hacía un par de años y no era la expresión, por lo menos a simple vista, de ninguna facción política. El decano de la prensa asuncena, como era conocido, no dedicó un renglón a las disquisiciones de Garay sobre la fundación de Asunción.

El único diario, de los que se conservan, que hizo una referencia fue La Libertad, que era un órgano de la facción caballerista del partido colorado, opositor a la facción que representaba el diario donde escribía Garay. Hará dos referencias en distintos días, el 12 de septiembre afirmaba “La Unión viene hecha un cuerpo sin cabeza, puso en sitio del artículo de relación viene usurpado por esa empalagosa, plagiria e inoportuna despotricación sobre la fundación de Asunción" (La Libertad, 12 de septiembre de 1894) y el día siguiente, el 13 fue un poco más lapidaria: 


\section{"El repertorio de los temas se había agotado para La Unión, el órgano de los seleccionados, pues ayer vino nuevamente con la chancha de "fundación de la Asun- ción», cosa que poco antes los escribidores del diario de la tesorería to do viene á salir lo mismo, puede de todos modos esa lechera produce el néctar ansiado para los alquilados." (La Libertad, 13 de septiembre de 1894)}

Los comentarios de La Libertad tienen un cariz político partidario claro. Garay era considerado un "escribidor" de un sector político, del egusquicismo,. Aparentemente la juventud estudiosa no estaba representada en La Libertad y aunque hayan sido "hijos de estas tierras" la fecha de la fundación de Asunción no era siquiera motivo de preocupación de sus redactores.

Surgen entonces nuevas dudas, ¿Garay tenía interlocutores? por lo que averiguamos con las fuentes a disposición afirmamos que no. Habrá que esperar hasta 1900 en que Manuel Domínguez y Manuel

\section{El trabajo del historiador}

Audibert le había propuesto al aficionado de La Unión que demostrase el "error en que se vivió"; días después Garay publicó siete artículos todos fir-
Gondra discutan sobre Schmidel y se refieran a estos artículos.

Vale decir que la escasa repercusión y la falta de interlocutores no avaló en nada a Garay. Tal es así entre enero y febrero de 1895 comenzó a publicar en el diario La Opinión "Observaciones críticas sobre Los Límites de la antigua provincia del Paraguay del Dr. Alejandro Audibert". Llegaron a publicarse diez extensos artículos. Coincidentemente el Dr. Audibert se llamó al silencio sobre los litigios con Bolivia y solo volvió a referirse a su obra y a sus aportes en 1901, dos años después de la muerte de Garay.

mados con su nombre, donde explicaba "vamos a hacer un ligero estudio sobre la fecha en qué fue fundada la ciudad de la Asunción, (...) fijada por casi 
todos los más notables historiadores en el 15 de Agosto de 1536 y que en concepto nuestro debe haber sido en el siguiente año de 1537." (La Unión, 10 de septiembre de 1894).

Pese a tomar el guante de corregir el error, el joven periodista lamentaba que no lo haya hecho Audibert, Io expresaba en estos términos "nuestro distinguido historiador, el doctor Audibert, que por la circunstancia de haber publicado recientemente una obra para la cual ha debido investigar el punto aludido por nosotros, estaba en las mejoras condiciones para hacer la luz en la materia." (La Unión, 10 de septiembre de 1894).

Ya embarcado en la tarea se aboca a explicar las causales de abordar su estudio "el deseo de atraer con nuestra iniciativa la investigación histórica sobre punto como este importantísimo $y$, según tenemos entendido, estudiado hasta hoy muy a la ligera y con escasísimo espíritu crítico." (La Unión, 10 de septiembre de 1894). Luego de esta evaluación sobre los estudios anteriores Garay comentaba las dificultades para hacer historia en Paraguay del periodo colonial en 1894

"A los que se dedican al cultivo de estas materias no se les ocultarán los inconvenientes y obstáculos con que habremos tropezado, habida en cuenta la enorme escasez de documentos y noticias, por lo muy poco que sobre ellos se ha escrito hasta ahora y por lo más poco aún que se posee en esta capital, donde están completamente dejadas de mano estudios de la índole del emprendido hoy por nosotros, en el deseo y con esperanza de que personas más autorizadas concluyen la obra." (La Unión, 10 de septiembre de 1894).

Pese a las divergencias de nuestros protagonistas la escasez de fuentes había sido señalada también por Audibert en el Prólogo "Los Límites..."

"reclamando de antemano
su indulgencia sobre una
materia conocida, pero
delicada por más de un
concepto, y llena de difi- 
cultades por la escasez de las obras ó fuentes a las cuales es necesario acudir para aclarar los límites de la antigua provincia del Paraguay, con los países que la circundan. Más la tarea era un deber en nosotros los hijos de aqueIla tierra, en presencia de la ruidosa reclamación diplomática de 1888." (Audibert, 1892: 05).

La segunda dificultad reconocida en el trabajo del historiador, común ambos autores era la falta de tiempo. Al respecto Garay justificaba

"Sirva pues, esta circunstancia (...) del escasísimo tiempo de que disponemos, de excusa a los errores talvez numerosos que de seguro hemos de cometer, y que, lo decimos con entera lealtad, agradeceremos nos sean señalados, pues no nos guía otro objeto que el de aclarar lo que nos parece muy oscuro, y nos pesaría mucho creery hacer creer disipadas sombras que no lo están." (La Unión, 10 de septiembre de 1894).
Recordemos que Audibert también había adjudicado a la "premura de la impresión" como causa de los errores cometidos en "Los Límites...".

El acceso a las fuentes y la falta de tiempo son argumentos utilizados por ambos autores para justificar sus errores y para reclamar indulgencia. Pero ese punto en común conduce a un diferencial. Garay justifica las causales de sus posibles errores y espera que le sean señalados, insistiendo en la importancia de que así se haga. Reconocemos en Garay una apertura hacia las críticas y las objeciones, entendiendo que estas ayudan a esclarecer puntos históricos fundamental de la historia nacional. Se podría suponer que es esta perspectiva la que incita a Garay a formular las críticas a Audibert. Como hemos señalado consideramos esta no eran la única causa. Siguiendo a Alejandro Eujanian interpretamos que "la crítica historiográfica se convirtió en el medio privilegiado para dirimir problemas vinculados a la competencia y legitimidad de aquellos que compartían el interés por dilucidar hechos del pasado o, con mayor ambición, desentrañar 
la trama que permitirá develar la verdad oculta tras los hechos." (Eujanian, 2003: p. 18).

Dijimos que Garay hablaba en representación de la juventud estudiosa, Manuel Gondra también formaba parte de este grupo. Ambos compartían la idea de la crítica como motor de esclarecimiento en la historia. Así al inicio de las críticas al Folleto sobre los próceres de la Independencia decía

\section{"hoy ya no se aceptan como verdades incontesta-} bles todas las afirmaciones que en sus obras hacen los escasos escritores, que se han ocupado en esbozar la historia paraguaya; la controversia conduce a la investigación erudita a los que tienen afición a este género de estudios, y si bien no se ha adelantado mucho todavía, hay por lo menos la fundadísima esperanza de que ello se conseguirá, pues es innegable que la discusión es fecunda, cuando los con- tenedores anteponen al propio el amor a la verdad." (Gondra, 1996: 89).

En las observaciones que le hacía específicamente a Audibert afirmaba "estas son las observaciones que nos ha sugerido de la lectura de su artículo, observaciones, que como dijimos más arriba, sólo van encaminadas a mover al erudito historiador a desvanecer las dudas que por el momento hay motivos de abrigar sobre los puntos" (Gondra, 1894: 89).

Pese a que Audibert pedía indulgencia en su Prólogo, el tenor y el objetivo de su libro no era discutir la veracidad con otros paraguayos y menos de aspectos como la fecha exacta de la fundación del fuerte de Asunción, sino sentar postura y definir una posición clara sobre un conflicto de límites con Bolivia que se venía arrastrando desde antes de la Guerra. Entonces la diferencia no es solo en la función de la crítica sino en la función social de la historia que los protagonistas le otorgan. 


\section{Como escribir historia}

Garay nunca redactó un manual del quehacer histórico, pero los artículos de crítica que publicó, a diferencia de sus libros "La revolución de la independencia" de 1897 o "El comunismo de las Misiones" de 1897, además de historiar cómo fue el hecho son una guía sobre cómo escribir historia. A partir de estos reconocemos qué pasos que debe seguir el historiador según Garay. Cabe aclarar que el autor no habla propiamente de pasos o etapas, es una estrategia que utilizamos para exponer el proceso de escritura de Garay.

El objetivo de los artículos era dilucidar la fecha de fundación del fuerte de Asunción, así la primera sugerencia es de contenidos: cuánto del contexto previo es necesario abordar para dilucidar la fecha de fundación. Una vez definidos los contenidos se pasa al siguiente paso: el acceso y la existencia de fuentes para desarrollarlas, que, como quedó expresado en las páginas anteriores, era un desafío en ese periodo. El tercer paso consiste en un análisis interno y externo de las fuentes a las que se acceden. Este será el paso más largo y al que Garay le dedica mayor cantidad de espacio en sus artículos. Realiza un trabajo pormenorizado con la obra de Schmidel. A partir de este análisis se revela la veracidad de los datos.

Surge así un nuevo problema, cómo debe proceder el historiador cuando las fuentes no proveen la información requerida. Es necesario recurrir al razonamiento análogo. El historiador debe basarse en situaciones análogas a lo que quiere historiar y partiendo de éstas, que deben estar debidamente especificadas con máximo detalle el hecho a historiar. Este procedimiento lo utilizar para determinar el tiempo aproximado de las expediciones que fundan. los diferentes fuertes "De mucho hubiera servido para nuestro intento el saber por qué tiempo estuvieron de vuelta en Corpus Christi los expedicionarios, más en la imposibilidad de averiguarlo con toda precisión, nos limitaremos a señalarla aproximadamente, valiéndonos de los pocos datos que tenemos, suficiente, sin embargo, para servirnos de guía." (La Unión, 15 de marzo de 1894). 
Se infiere que esta forma de hacer historia expuesta por Garay fue aprendida a través de las lecturas de textos que habría leído en su corta vida, pero hacemos hincapié, también, en lo aprendido en el Colegio Nacional (Gomez, 2019 b). Durante su instrucción secundaria en la asignatura "Elementos de Lógica" tenían tres lecciones, de un total de veinte y dos, dedicadas exclusivamente al método histórico como parte del método de las Ciencias Morales (Gomez, 2019 b: p. 52).

Sobre la delimitación de los contenidos para llegar a la fecha certera de fundación del fuerte de Asunción era necesario, primero definir la fecha exacta de la expedición que partió de España con los protagonistas de la fundación. Luego determinar las fechas de creación de los fuertes de Nuestra Señora de Buenos Aires y luego el de Corpus Christi, para recién abordar el de Asunción

"Para dar algún orden a este trabajo, empezaremos por historiar la expedición del adelantado don Pedro de Mendoza, fijando la fecha de su salida de España, pues estando basados en ellas todas las posteriores (...), es un punto de partida imprescindible para nuestras investigaciones, importa por consiguiente, mucho dejarlo bien determinado, sin dar lugar a la duda, de manera que en él se apoya toda nuestra argumentación; y esto explicara el porqué de estudiarlo con tanta minuciosidad." (La Unión, 10 de septiembre de 1894).

Luego de tres largos artículos y haber analizado a más de quince fuentes Garay afirmaba: 
ciones que haremos después sobre la de la fundación del fuerte bautizado con el nombre de Nuestra Señora de la Asunción." (La Unión, 12 de marzo de 1894).

La minuciosidad es transversal al trabajo del historiador: debe aparecer tanto en los contenidos como en las fuentes consultadas y utilizadas, como en el análisis practicado a éstas. “Entendemos que nunca esta demás la minuciosidad en la argumentación, principalmente cuando se trata de un asunto que, (...), debe procurarse dejar perfectamente dilucidado, por la importancia que tiene como punto de partida para fijar la fecha de acontecimientos posteriores." (La Unión, 12 de marzo de 1894). Ya probada sin margen de dudas la fecha de partida de Mendoza se deben determinar cronológica y correctamente la fundación del fuerte de Nuestra Señora de Buenos Aires y seguidamente la fundación del fuerte de Corpus Christi y luego historiar el de Asunción. Este era el contenido temático que debería haber tenido la obra de Audibert para Garay.

"Historiadores poco minuciosos, que no han sabido percatarse de la impor- tancia que siquiera sea desde el punto de vista cronológico tiene la fundación del fuerte de Corpus Christi, han omitido decir palabra de ella (Barco ...) o no han distinguido con la necesaria claridad esta incursión de Oyolas de la que emprendió meses después para fundar la Asunción (Guevara .... Alvear ...; P. Bautista...). En las mismas faltas incurre nuestro Dr. Audibert en su obra "Los límites ..." (pág. 47) con agravante muy digno de ser tenido en cuenta, lo de la reincidencia, cometido en el poco feliz reportaje que publicó en "El Pueblo" del 5 de este mes." (La Unión, 15 de marzo de 1894).

La importancia de la fundación del fuerte de Corpus Christi radicaba en que había sido fundado por Oyolas 4 previamente. Estudiar su fundación e identificar correctamente cuando sucedió daba orden temporal

$4 \quad$ Con este nombre se refiere Garay a Ayolas. 
a la creación del fuerte de la Asunción. Así justificaba su decisión "el que los escritores citados hayan mirado como cosa de poco monta esta empresa, no le quita, sin embargo, nada del valor que tiene; reconocido por numerosos autores que la mencionan y hablan de ella con bastante detenimiento." (La Unión, 15 de marzo de 1894).

\section{Análisis interno y externo de fuentes}

Habíamos visto que Audibert sostenía que la fundación del fuerte de Asunción se produjo en 1536 siguiendo a Lozano, Garay afirmaba que había sido en 1537 y Schmidel en su texto "Historia y descubrimiento del Rio de la Plata y Paraguay" afirmaba que se produjo en 1539.

Audibert cita a Schmidel, únicamente, porque fue un testigo ocular de los hechos, en ningún momento explicita que está de acuerdo con las fechas indicadas por el solado bávaro. Detalle ignorado por Garay en tanto dedica gran parte de sus artículos a demostrar que Schmidel estaba equivocado y más aún lo estaban los autores posteriores que lo seguían. No obstante, es enriquecedor describir el minucioso y detallado proceso que sigue el joven periodista para desacreditar el uso de Schmidel y mostrar todas las opciones posibles para suplantarlo.
Comienza entonces, explicando porque Schmidel es tenido en cuenta para historiar el periodo y los sucesos: "hemos hablado de Schmidel, que en calidad de soldado figuraba en esta expedición (...) vuelto al cabo de veinte años a su patria, compuso guiado por sus recuerdos y sin tener a la vista ningún documento, la historia de su viaje que tiene por consiguiente todo el mérito y la verosimilitud de la narración de un testigo presencial". (La Unión, 11 de septiembre de 1894).

En la lección XVIII de los Elementos de Lógica que Garay cursó en su secundario se veían los siguientes contenidos "Método de las ciencias históricas: el testimonio de los hombres: su importancia. Fundamento del testimonio. Aplicaciones del testimonio humano. Reglas: unidad y pluralidad de testigos. Los hechos. Certeza del testimonio. Testimonio en 
materia de doctrina. El tradicionalismo." (Gomez, 2019 b: p. 52). En las citas siguientes veremos cómo los lleva a la práctica.

"La obra de Schmidel está (...) plagada de muchas inexactitudes, señaladas por los historiadores que escribieron después de él particularmente por Azara, y esta circunstancia nos obliga aún más a someter sus aseveraciones al crisol de la crítica antes de aceptarlas como verdaderas, para no admitir lo que no haya resistido a ella." (La Unión, 11 de septiembre de 1894, la cursiva es nuestra).

Garay se concentra en quién fue el autor, cuándo escribió, porqué escribió, en qué idioma lo hizo y cual era la evaluación que otros historiadores ya habían realizado sobre este. Así la interpretación de Félix de Azara (1746-1821) era una vara de seriedad y veracidad.

La última frase de la cita es contundente, teniendo en cuenta que Audibert en su libro cita las fuentes sin hacer ningún tipo de análisis explícito de la veracidad de estas. Es importante no perder de vista que la minuciosidad que Garay exige a
Audibert no cuadra con el objetivo de "Los límites...", que era dar herramientas al Estado para justificar sus derechos sobre los territorios del Chaco. Detalles como la fecha exacta de la fundación de Asunción eran intrascendentes en este marco. En la misma lógica se encuadra el reclamo del no haber desarrollado la fundación de todos los fuertes creados previamente a la fundación de la Asunción.

Reconocemos otra característica de los libros de historia para la concepción de Garay, estos no solo deben contar la historia sino que además deben explicitar el análisis minucioso de las fuentes utilizadas para construir el relato. El historiador debe dialogar fluidamente con sus fuentes.

En el Prólogo de "Los límites..." Audibert explicaba su proceder historiográfico 
resultado ha sido hacer un acópio de conocimientos que revelan esta propensión de apoderarme de lo ageno. El fruto de este trabajo es escribir cuantos párrafos y artículos he entresacado de las obras que hasta ahora han llegado á mis manos y son conducentes al fin que me he propuesto omitiendo lo incongruentes y espresando lo que concierne al caso. No son cosas nuevas para los que conocían las obras; pero para los que no tienen noticias de la historia y de los hechos, es de mucha utilidad que se generalicen.» (Audibert, 1892: 21, la cursiva es nuestra).

Omitir lo incongruente y expresar lo que concierne al caso, hacer un acopio de los contenidos de los otros autores. En ningún momento expresa cuál será el criterio utilizado identificar lo incongruente o qué criterio utilizará para elegir entre las distintas versiones que se presentan sobre los mismos hechos.
Peña hablaba de acopiar conocimiento y la acción del acopio remite a juntar y/o reunir en cantidad algo, ahora bien compulsar que es la acción propuesta por Garay consiste en cotejar una copia con el documento original para determinar su exactitud y sobre eso decidir la originalidad.

Garay critica el aspecto compilativo de la obra de Audibert porque le quita claridad y veracidad a la exposición al mostrar todas las opciones existentes, no queda claro cuál es la verdadera.

Expresa cierta negligencia en el proceder del jurista en el sentido que para él está obra era el fundamento que dejaba en evidencia los derechos históricos del Paraguay sobre el Chaco. El punto que saca a luz Garay con sus críticas es que el trabajo de evidenciar los derechos fue flojo e impreciso y en tal sentido cualquier boliviano podría llegar a hacer el mismo análisis y desarticular los argumentos que se suponen hacían algún aporte a la patria. 


\section{Reflexiones finales}

El tema central de la crítica

Esta forma de concebir la de Blas Garay al Dr. Alejandro Audibert era la fecha exacta de la fundación del fuerte de Nuestra Señora de la Asunción. Hemos señalado también que pese a la minuciosidad y la probidad científica con que fue realizada, estaba motivada por intereses sociopolíticos. Insistimos en que este aspecto no le quita validez a la crítica sino que, por el contrario, demuestra lo imbricado que está el relato histórico con el presente de quien lo escribe y la necesidad de abordarlo a la hora de analizar críticas históricas.

Los términos en que fue realizada la crítica del joven periodista demuestran una concepción de historia donde el documento es fundamental en tanto construye y demuestra el relato histórico, pero más aún lo es el análisis que el historiador debe hacerle al documento. Al narrar la fundación de Asunción el historiador debe investigar con relatos de "testigos presenciales", aspecto que es considerado por varios autores como prueba suficiente de veracidad. Es contra este prepuesto que discutirá Garay y exigirá el análisis pormenorizado de estos relatos.

historia era una de las posibles, otra manera estaba representada en el pensamiento y la obra de Audibert. En este sentido revisar la discusión que existió entre los autores permite evidenciar estas formas paralelas de hacer historia que coexistían en la Asunción de fin de siglo. La minuciosa confrontación de Garay, que será la primera de varias, es un claro indicador de que había un sector de la elite intelectual que bregaba por instalar una historia de carácter más científico y erudito, acorde a los parámetros de la época a nivel internacional.

Queremos resaltar que las prédicas de ambos protagonistas no fueron en vano. El reclamo de Audibert resultó en el viaje de Garay a España para buscar documentos históricos que probarán la propiedad del Paraguay sobre los territorios del Chaco: lo que puede considerarse como un cambio fundamental en las políticas de las relaciones internacionales. Los derroteros de la historia muestran que, lo que tanto quisieron evitar los hombres del periodo, un conflicto 
bélico entre países hermanos, con fuentes documentales y fue inevitable años después. con análisis pormenorizado de estas, 120 años después

La prédica de Garay por de su muerte lamentablemente la elaboración de una historia sigue siendo aún necesaria. 


\section{Referencias bibliográficas}

Amaral, R. 2006. El novecentismo paraguayo. Hombre e ideas de una generación fundamental del Paraguay, Asunción, Servilibro.

Brezzo, L. 2008. "En el mundo de Ariadna y Penélope": hilos, tejidos y urdiembre del nacimiento de la historia en el Paraguay. Consideraciones en torno a la polémica Cecilio Báez -Juan O'Leary, en Báez, Cecilio y O'Leary, Juan E. Polémica sobre la Historia del Paraguay, Asunción, Tiempo de Historia, pp. 11-65.

Brezzo, L. 2009. “Paraguay en cinco momentos historiográficos: retos y perspectivas", en Casal, J. y Whigham, T. (ed.) Paraguay: el nacionalismo y la Guerra, Asunción, Servilibro, pp. 61-78.

Brezzo, L. 2010. "Reparar la nación” discursos históricos y responsabilidades nacionalistas en Paraguay. Historia Mexicana, Vol. LX, n 1, julio septiembre, pp. 197-242.

Brezzo, L. 2011. “La Historia y los historiadores”, en Telesca, I. (coord.) Historia del Paraguay, Asunción, Taurus, pp. 19-40.

Cano Radil, B. 2011. Blas Garay, Asunción, El Lector.

Cardozo, E. 1959. Historiografía Paraguaya. Instituto Panamericano de Geografía e Historia.

Centurión, C. 1948. Historia de las Letras Paraguayas. II Época de transformación. Buenos Aires. Editorial Asunción.

Chesterton, B. 2013. The Grandchildren of Solano López. Frontier and nation in Paraguay, 1904 -1936, Albuquerque, New Mexico.

Doratioto, F. 2011Una relación compleja. Paraguay y Brasil 1889-1954, Asunción, Tiempo de Historia.

Eujanian, A. 2003. "El surgimiento de la crítica", en Cattaruzza, A. y Eujanian, A. Políticas de la historia argentina 1860-1960, Buenos Aires, Madrid: Alianza Editorial, pp. 17-41.

Fuentes Armadans, C.J. En Prensa. "Sarmiento vs. Cañete: Polémica previa al surgimiento del novecentismo", en Whigham, T. y Casal, J. (eds.). Memorias de las V y VI Jornadas Internacionales de Historia del Paraguay, Asunción, Tiempo de Historia.

Gómez, B. 2016. “Verdad e historia en "La revolución de la Independencia” de Blas Garay" Estudios Paraguayos, Vol. XXXIV, Asunción, pp. 65-85.

Gómez, B. 2017. “La figura del Dr. Francia en la historiografía paraguaya posbélica: la batalla por los héroes", Temporalidades Revista de Historia, Ediçao 23, Vol. 9, n 1, janeiro - abril, pp. 56-79. 
Gómez, B. 2019 a. “Instituto Histórico del Paraguay 1895-1896”, Revista Paraguaya de Historia. Vol. II, n¹, Asunción, pp. 125-151.

Gómez, B. 2019 b. “Formas de hacer historia en el Paraguay finisecular. El caso de Blas Garay", en Squinelo, A. y Telesca, I. (Org.), 150 anos após a Guerra do Paraguai: entreolhares do Brasil, Paraguai, Argentina e Uruguai, Campo Grande: Life editora, pp. 35-58.

Herken Krauer, J.C. 1984. El Paraguay rural entre 1869 y 1913, Asunción, Centro Paraguayo de Estudios Sociológicos.

Kleinpenning, J. 2011. Paraguay 1515-1870. Una geografía temática de su desarrollo, Asunción, Tiempo de Historia.

Lewis, P. 1993. Partidos políticos y generaciones en Paraguay 1869-1940, Asunción, Tiempo de Historia.

Rivarola Paoli, J.B. 2012. Historia de la Instrucción pública en el Paraguay, Asunción, FONDEC.

Sansón Corbo, T. 2015. Despertar en Petropolis. Andrés Lamas y la influencia de Brasil en la historia de los estados de la Cuenca del Plata en el siglo XIX. Montevideo, Sicut Serpentes.

Sansón Corbo, T. 2019. El adiós a los grandes maestros. Juan Pivel devoto y la Historia de América en las décadas definitorias (1930-1950), Montevideo, Archivo General de la Nación.

Scavone Yegros, R. 2004. Las relaciones entre Paraguay y Bolivia en el siglo XIX, Asunción, Servilibro.

Telesca, I. 2012. "Blas Garay y el "Prólogo" a del Techo: inventando al Paraguay". En Telesca I. e Insaurralde, G. (ed.) Melià... escritos de homenaje, Asunción, ISEHF, pp. 243-264.

Telesca, I. 2013. “La República de los historiadores del Paraguay posbélico", Anuario de la Academia Paraguaya de la Historia, Vol. LIII, Asunción, pp. 123-136.

Warren, H. 1985. La reconstrucción del Paraguay, 1878 -1904, Asunción: Intercontinental Editora.

\section{Fuentes hemerográficas}

El Pueblo, junio, agosto, septiembre de 1894. Asunción. Paraguay.

El Independiente, enero de 1893. Asunción. Paraguay.

La Unión, septiembre de 1894. Asunción. Paraguay.

La Libertad, septiembre 1894. Asunción. Paraguay. 


\section{Otras fuentes}

Audibert, A. 1892. Los límites de la Antigua Provincia del Paraguay. Primera parte, Buenos Aires, Imprenta La Económica de Iustoni Hnos \& Cia.

Gondra, M. 1996 [1948] Hombres y letrados de América, Asunción, El Lector.

Registro Oficial de la República del Paraguay año 1893. Asunción. 1895.

Registro Oficial de la República del Paraguay año 1895. Asunción. 1896.

Revista de la Universidad Nacional 1895. Año III. Asunción. 1895. 